\title{
PENGARUH PERILAKU DAN LINGKUNGAN FISIK TERHADAP KEJADIAN MALARIA DI DESA ALIM MEBUNG DAN DESA NURBENLELANG KABUPATEN ALOR PROVINSI NTT TAHUN 2018
}

\author{
Menason Jeterianus Jella ${ }^{1}$, Muh. Basri ${ }^{2}$, Masriadi ${ }^{3}$ \\ ${ }^{1}$ Pascasarjana Universitas Muslim Indonesia \\ ${ }^{2}$ Pascasarjana Universitas Muslim Indonesia \\ ${ }^{3}$ Pascasarjana Universitas Muslim Indonesia \\ Alamat korespondensi : (menasonjella@gmail.com/081342531931)

\begin{abstract}
ABSTRAK
Malaria adalah satu penyebab utama morbiditas, mortalitas, dan bersifat endemik di negara tropis dan sub-tropis. Penelitian ini dilakukan untuk menganalisis pengaruh perilaku dan lingkungan fisik terhadap kejadian malaria. Desaian penelitian ini adalah explanatory riset. Jumlah populasi sebesar 212 (total populasi). Teknik analisis adalah Structural Equation Modeling dengan program Lisrel 8,7. Hasil penelitian pengaruh langsung antara pengetahuan nilai $t$-vulues $-0,51$, dan sikap nilai $t$-vulues $0,76,(<1,96)$ terhadap lingkungan fisik. Pengaruh langsung antara pengetahuan nilai $t$ vulues 2,89, sikap nilai $t$-vulues 2,72 , dan lingkungan fisik nilai $t$-vulues 10,56, $(>1,96)$ dengan kejadian malaria. Pengaruh tidak langsung antara pengetahuan nilai $t$-vulues 2,89 , dan sikap nilai $t$ vulues $-2,72(>1,96)$ kejadian malaria melewati lingkungan fisik. Kesimpulan dalam penelitian ini terdiri dari 3 kategori yaitu: 1. Pengetahuan lingkungan fisik memiliki pengaruh langsung terhadap kejadian malaria dan sikap tidak memiliki pengaruh langsung terhadap lingkungan fisik; 2. Pengetahuan, sikap dan lingkungan fisik memiliki pengaruh langsung terhadap kejadian malaria; 3. Pengetahuan dan sikap memiliki pengaruh terhadap kejadian malaria melawati lingkungan fisik.
\end{abstract}

Kata Kunci: Pengetahuan, Sikap, Lingkungan Fisik, Kejadian Malaria

\section{PENDAHULUAN}

Malaria merupakan salah satu penyebab utama morbiditas dan mortalitas di negara tropis dan sub-tropis (Kebede dkk. 2017), yang mempengaruhi orang dari semua kelompok umur, bersifat endemik di 109 negara, mencakup semua benua (Khairy dkk. 2017).

Faktor lingkungan dan pola perilaku vektor dan populasi manusia bergabung untuk memberikan kondisi yang menguntungkan untuk penularan malaria (Adebayo dkk. 2015).

Kondisi lingkungan memiliki potensi untuk. Tujuan dari WHO untuk mengakhiri epidemi malaria pada tahun 2030 terletak pada komitmennya untuk melanjutkan untuk berinvestasi dalam mengubah perilaku orangorang, Pendekatan gender untuk memahami pengetahuan, sikap dan praktik malaria dan kontrolnya diperlukan karena norma gen mempengaruhi pola kerja, waktu luang dan tidur, yang selalu mempengaruhi paparan nyamuk. (Yaya dkk. 2017).

Tahun 2014, 97 negara dan wilayah memiliki transmisi malaria yang berkelanjutan. Diperkirakan 3,3 miliar orang berisiko malaria, di antaranya 1,2 miliar berisiko tinggi. $\mathrm{Di}$ daerah berisiko tinggi, lebih dari satu kasus malaria terjadi per 1000 penduduk (WHO, 2014),

Kawasan Asia Tenggara juga menjadi perhatian kasus malaria. Terdapat 1,4 miliar penduduk berisiko terkena malaria, dan 352 juta pada risiko tinggi (WHO, 2014). Angka kesakitan malaria selama tahun 2009-2016 cenderung menurun yaitu dari 1,8 per 1.000 penduduk berisiko pada tahun 2009 menjadi 0,84 per 1.000 penduduk berisiko pada tahun 2016. Papua merupakan provinsi dengan Annual Parasite Incidence (API) tertinggi, yaitu 45,85 per 1.000 penduduk. Angka ini sangat tinggi jika dibandingkan dengan provinsi lainnya. Empat provinsi dengan API per 1.000 penduduk tertinggi lainnya, yaitu Papua Barat $(10,20)$, Nusa Tenggara Timur $(5,17)$, Maluku $(3,83)$, dan Maluku Utara $(2,44)$. Sebanyak $83 \%$ kasus berasal dari Papua, Papua Barat, dan Nusa Tenggara Timur (KemenkesRI, 2016).

Penyakit Malaria merupakan salah satu penyakit yang menjadi masalah kesehatan di Provinsi NTT, dimana penyakit ini masih menjadi penyebab kematian bagi bayi, balita dan ibu hamil serta dapat menurunkan produktifitas tenaga. Provinsi NTT hampir $100 \%$ desa umumnya barasal dari desa 
terpencil dengan kondisi lingkungan yang tidak baik. (Dinkes Prov NTT, 2015).

Data Dines Kesehatan Kabupaten Alor kasus malaria positif pada tahun 2014 sebanyak $1.935(46,63 \%)$ kasus, pada tahun 2015 sebanyak 1835 (45,34\%) kasus, pada tahun 2016 sebanyak $2.005(47,31 \%)$ kasus, pada tahun 2017 sebanyak 1.635 (43,95\%) kasus dan pada tahun 2018 sebanyak 1.435 $(41,1 \%)$ kasus malaria (Dinkes Kab Alor, 2018).

Data puskesmas Mebung Dalam lima tahun terakhir, jumlah kasus Malaria di Puskesmas Mebung berfluktuasi. Pada tahun 2014 terdapat 250 (8,5\%) kasus malaria, kemudian mengalami Kenaikan menjadi 310 (9\%) kasus pada tahun 2015, kembali meningkat menjadi $337 \quad(9,2 \%)$ kasus, kemudian mengalami Kenaikan menjadi 394 $(9,9 \%)$ pada tahun 2016 dan kembali Menurun 290 (8,9\%) (Puskesmas Mebung, 2018).

Berdasarkan beberapa hal di atas, peneliti bermaksud melakukan penelitian tentang "Pengaruh Perilaku Dan Lingkungan Fisik Terhadap Kejadian Malaria di Desa Alim Mebung dan Desa Nurbenlelang Kecamatan Alor Tengah Utara Kabupaten Alor Provinsi NTT tahun 2018"

\section{BAHAN DAN METODE}

Lokasi, Populasi, Sampel

Penelitian ini dilaksanakan di desa Alim Mebung dan Desa Nurbenlelang pada tanggal 12 oktober-15 november 20-18. Populasi dalam penelitian ini sebanyak 212 responden yang mengalami kejadian Malaria positif dan suspek 2018. Sampel dalam penelitian ini adalah total Sampling berjumlah 212 positif malaria dan suspek, Desa Alim Mebung berjumlah 106 positif malaria, suspek dan Desa Nurbenlelang berjumlah 106 positif malaria, suspek.

1. Kriteria inklusi:
a. Bersedia penelitian.
berpartisipasi dalam
b. Tercatat sebagai penderita malaria positif yang telah diambil sediaan darahnya yang dinyatakan berdasarkan hasil pemeriksaan di laboratorium Dan malaria suspek
c. Warga Desa Alim Mebung dan Desa Nurbenlelang
d. Berumur $11-55$ tahun

2. Kriteria eksklusi:
a. Tidak bersedia berpartisipasi dalam Penelitian
b. Bukan warga desa Alim Mebung dan Desa Nurbenlelang
c. Berumur di bawah 11 dan di atas 56 tahun

\section{Pengumpulan Data}

1. Data sekunder adalah data yang diperoleh dalam bentuk yang telah diolah oleh pihak lain dalam bentuk publikasi.

2. Data primer adalah data yang dikumpulkan dan diolah sendiri.

\section{Pengolahan Data}

\section{Editing}

tahapan pemeriksaan validitas data yang masuk seperti memeriksa kelengkapan pengisian kuesioner, kejelasan jawaban, relevansi jawaban dan keseragaman suatu pengukuran.

3. Coding

tahapan mengklasifikasi data dan jawaban menurut kategori masing-masing sehingga memudahkan dalam pengelompokan data.

2. Processing

tahapan memproses data agar dapat dianalisis. Pemrosesan data dilakukan dengan cara memasukkan data hasil pengisian kuesioner ke dalam master tabel.

3. Cleaning

tahapan pengecekan kembali data yang sudah di masukkandan melakukan koreksi bila terdapat kesalahan. (Lapau, 2013).

Analisis Data

1. Analisis Univariat

Hasil dari penelitian ditampilkan dalam bentuk distribusi frekuensi.

2. SEM

Teknik analisis data yang digunakan dalam penelitian ini adalah Structural Equation Modeling (SEM) dengan mengunakan bantuan softwere LISREL release 8.7 .

\section{HASIL PENELITIAN}

1. Analisis Univariat

Tabel 1 Distribusi karakteristik responden Di desa Alim Mebung dan desa Nurbenlenag tahun 2018. $(\mathrm{n}=212)$

\begin{tabular}{|c|c|c|}
\hline Variabel & $\mathrm{n}$ & $\%$ \\
\hline Malaria & & \\
Positif & 106 & 50,0 \\
Suspek & 106 & 50,0 \\
\hline $\begin{array}{c}\text { Lingkungan } \\
\text { Cukup }\end{array}$ & 72 & 34,0 \\
Kurang & 140 & 66,0 \\
\hline $\begin{array}{c}\text { Pengetahuan } \\
\text { Cukup }\end{array}$ & 8 & 3,8 \\
Kurang & 204 & 96,2 \\
\hline Sikap & & \\
Cukup & 33 & 15,6 \\
Kurang & 179 & 84,4 \\
\hline
\end{tabular}

Dari tabel 1 menunjukkan dari 212 Menunjukan bahwa Kejadian malaria positif 
sama banyak dengan suspek yaitu $50,0 \%$. Lingkungan fisik yang kurang $66,0 \%$, lebih banyak dari pada yang cukup $34,0 \%$. Pengetahuan kurang $96,2 \%$, lebih banyak dari pengetahuan cukup 3,8\%. Sikap kurang pengaruh antar variabel secara langsung dan tidak langsung dapat di sajikan sebagai berikut:

a. Variabel independen pengetahuan berpengaruh negatif secara langsung dan tidak signifikan terhadap variabel interfening lingkungan fisik dengan nilai $t$-values $-0,51<1,96$.

b. Variabel independen sikap berpengaruh positif secara langsung dan tidak signifikan terhadap variabel interfening lingkungan fisik dengan nilai $t$-values $0,76<1,96$.

c. Variabel independen pengetahuan berpengaruh negatif secara langsung dan signifikan terhadap variabel dependen kejadian malaria dengan nilai $t$-values 2,89 > 1,96

d. Variabel independen sikap berpengaruh negatif secara langsung dan signifikan terhadap variabel dependen kejadian malaria dengan nilai $t$-values $2,72>$ $1,9684,4 \%$, lebih banyak dari pada bersikap baik $15,6 \%$.

2. Analisis SEM

Tabel 2 pengaruh langsung dan tidak langsung

\begin{tabular}{|c|c|c|c|c|c|}
\hline \begin{tabular}{|c|} 
Variabe \\
I \\
Indepe \\
n den \\
\end{tabular} & $\begin{array}{c}\text { Variabel } \\
\text { Interveni } \\
\text { ng }\end{array}$ & $\begin{array}{c}\text { Variabel } \\
\text { depende } \\
n\end{array}$ & $\begin{array}{c}\text { Esti } \\
\text { mas } \\
i\end{array}$ & $\begin{array}{c}\mathrm{t}- \\
\text { Val } \\
\text { ues }\end{array}$ & $\begin{array}{c}\text { Ketera } \\
\text { ngan }\end{array}$ \\
\hline $\begin{array}{c}\text { Penget } \\
\text { a } \\
\text { huan } \\
\end{array}$ & $\begin{array}{l}\text { Lingkung } \\
\text { an fisik }\end{array}$ & & $0, \overline{14}$ & $\begin{array}{c}0,5 \\
1\end{array}$ & $\begin{array}{c}(-) \\
\text { Tidak } \\
\text { Sig }\end{array}$ \\
\hline Sikap & $\begin{array}{l}\text { Lingkung } \\
\text { an fisik }\end{array}$ & & $0,07 \mid$ & $\begin{array}{c}0,7 \\
6\end{array}$ & $\begin{array}{c}(+) \\
\text { Tidak } \\
\text { Sig }\end{array}$ \\
\hline \begin{tabular}{|c|} 
Penget \\
a \\
huan \\
\end{tabular} & & $\begin{array}{c}\text { Kejadian } \\
\text { malaria }\end{array}$ & 0,18 & $\begin{array}{c}2,8 \\
9\end{array}$ & (+) Sig \\
\hline \multirow[t]{2}{*}{ Sikap } & & $\begin{array}{c}\text { Kejadian } \\
\text { malaria }\end{array}$ & 0,16 & $\begin{array}{c}2,7 \\
2 \\
\end{array}$ & (+) Sig \\
\hline & $\begin{array}{l}\text { Lingkung } \\
\text { an fisik }\end{array}$ & $\begin{array}{c}\text { Kejadian } \\
\text { malaria }\end{array}$ & $0,80 \mid$ & $\begin{array}{l}10, \\
56 \\
\end{array}$ & (+) Sig \\
\hline \begin{tabular}{|c|} 
Penget \\
$a$ \\
huan
\end{tabular} & $\begin{array}{c}\text { lingkunga } \\
\text { n Fisik }\end{array}$ & $\begin{array}{c}\text { Kejadian } \\
\text { malaria }\end{array}$ & 0,18 & $\begin{array}{c}2,8 \\
9\end{array}$ & (+) Sig \\
\hline Sikap & $\begin{array}{c}\text { lingkunga } \\
\text { n Fisik }\end{array}$ & $\begin{array}{c}\text { Kejadian } \\
\text { malaria }\end{array}$ & $\begin{array}{c}- \\
0,16\end{array}$ & $\begin{array}{c}2,7 \\
2\end{array}$ & (-) Sig \\
\hline
\end{tabular}

a. Variabel intervening lingkungan fisik berpengaruh negatif secara langsung dan signifikan terhadap variabel dependen kejadian malaria dengan nilai t-values $10,56>1,96$

b. Variabel independen pengetahuan berpengaruh positif secara tidak langsung dan signifikan terhadap variabel dependen malaria melewati variabel intervening lingkungan fisik dengan nilai $t$-values $2,89>1,96$

c. Variabel independen sikap berpengaruh negatif secara tidak langsung dan signifikan terhadap variabel dependen malaria melewati variabel intervening lingkungan fisik dengan nilai $t$-values $2,72>1,96$

\section{PEMBAHASAN}

1. Pengaruh Langsung Pengetahuan Terhadap Lingkungan Fisik Di Desa Alim Mebung Dan Desa Nurbenlelang Kecamatan Alor Tengah Utara Kabupaten Alor Provinsi NTT Tahun 2018.

Uji hipotesis dengan pendekatan SEM menghasilkan koefisien jalur pengaruh langsung pengetahuan terhadap lingkungan fisik dengan nilai $t$-vulues $-0,51$ sehinga hubungan antara kedua jalur variabel tersebut tidak signifikan. Penelitian yang di lakukan di kedua desa tersebut dengan cara observasi langsung dan wawancara membuktikan bahwa pengetahuan kurang, tidak berarti tidak menjaga lingkungan fisik bahkan sebaliknya dapat menjaga lingkungan fisik.

Pengetahuan adalah hasil tahu dan ini terjadi setelah orang melakukan penginderaan terhadap suatu objek tertentu. Sebagian besar pengetahuan manusia diperoleh melalui mata dan telinga (Notoatmodjo, 2011).

Pengetahuan dipengaruhi oleh faktor pendidikan formal. Pengetahuan sangat erat hubungannya dengan pendidikan, dimana diharapkan bahwa dengan pendidikan tinggi maka orang tersebut akan makin luas pengetahuannya. (Wawan \& Dewi, 2010).

2. Pengaruh Langsung Sikap Terhadap Lingkungan Fisik Di Desa Alim Mebung Dan Desa Nurbenlelang Kecamatan Alor Tengah Utara Kabupaten Alor Provinsi NTT Tahun 2018

Uji hipotesis dengan pendekatan SEM menghasilkan koefisien jalur pengaruh langsung sikap terhadap lingkungan fisik dengan nilai $t$-vulues 0,76 sehinga hubungan antara kedua jalur variabel tersebut tidak signifikan. Penelitian yang di lakukan di kedua desa tersebut dengan cara observasi langsung dan wawancara membuktikan bahwa Sikap 
cukup, berarti menjaga lingkungan fisik bahkan sebaliknya sikap yang kurang tidak dapat menjaga lingkungan fisik.

Sikap adalah respon tertutup seseorang terhadap stimulus atau objek tertentu, yang sudah melibatkan faktor pendapat dan emosi yang bersangkutan. (Campbell 1950 dalam Ora, Widjanarko \& Udijono, 2015) mendefinisikan bahwa sikap itu suatu sindrom atau kumpulan gejala dalam merespons stimulus atau objek. Sehingga sikap itu melibatkan pikiran, perasaan, perhatian, dan gejala kejiwaan yang lain.

3. Pengaruh Langsung Pengetahuan Terhadap Kejadian Malaria Di Desa Alim Mebung Dan Desa Nurbenlelang Kecamatan Alor Tengah Utara Kabupaten Alor Provinsi NTT Tahun 2018

Uji hipotesis dengan pendekatan SEM menghasilkan koefisien jalur pengaruh langsung pengetahuan terhadap kejadian malaria dengan nilai $t$-vulues 2,89 sehinga hubungan antara kedua jalur variabel tersebut signifikan.

4. Pengaruh Langsung Sikap Terhadap Kejadian Malaria Di Desa Alim Mebung Dan Desa Nurbenlelang Kecamatan Alor Tengah Utara Kabupaten Alor Provinsi NTT Tahun 2018

Uji hipotesis dengan pendekatan SEM menghasilkan koefisien jalur pengaruh langsung sikap terhadap kejadian malaria dengan nilai $t$-vulues 2,72 sehinga hubungan antara kedua jalur variabel tersebut signifikan. Penelitian yang di lakukan di kedua desa tersebut dengan cara observasi langsung dan wawancara membuktikan bahwa sikap yang kurang, berarti akan akan terinfeksi kejadian malaria bahkan sebaliknya sikap yang cukup dapat mencega kejadian malaria.

Meningkatkan kesadaran, sikap, dan perilaku masyarakat juga membantu mengurangi jumlah kasus malaria. Untuk menghilangkan penyakit dan mencegah terjadinya penyakit malaria, sehingga perlu meningkatkan pengetahuan masyarakat tentang pengendalian dan pengobatan malaria. Selain itu, harus ada program pendidikan kesehatan untuk meningkatkan pengetahuan dan perilaku hidup bersih dan sehat pada masyarakat dalam melindungi pribadi dan keluarganya dan perbaikan lingkungan untuk mencegah terciptanya lingkungan baru sebagai wadah perkembangan malaria (Khairy et al., 2017 dalam Halid, 2018).

5. Fisik Terhadap Kejadian Malaria Di Desa Alim Mebung Dan Desa Nurbenlelang
Kecamatan Alor Tengah Utara Kabupaten Alor Provinsi NTT Tahun 2018

Uji hipotesis dengan pendekatan SEM menghasilkan koefisien jalur pengaruh langsung lingkungan fisik terhadap kejadian malaria dengan nilai $t$ vulues 10,56 sehinga hubungan antara kedua jalur variabel tersebut signifikan.

Penelitian yang di lakukan di kedua desa Menurut (Noviarti, Joko \& Dewanti, 2016), terdapat hubungan antara keberadaan langit-langit, jenis dinding, keberadaan resting places, breeding places, aktivitas luar rumah, penggunaan pakaian panjang, penggunaan kelambu, dan kegiatan bersih lingkungan dengan kejadian malaria.

Pengaruh Tidak Langsung pengetahuan Terhadap Kejadian Malaria Melewati Lingkungan Fisik Di Desa Alim Mebung Dan Desa Nurbenlelang Kecamatan Alor Tengah Utara Kabupaten Alor Provinsi NTT

Uji hipotesis dengan pendekatan SEM menghasilkan koefisien jalur pengaruh tidak langsung pengetahuan terhadap kejadian malaria melewati lingkungan fisik dengan nilai $t$-vulues 2,89 sehinga hubungan antara ketiga jalur variabel tersebut signifikan.

Pengetahuan sangat erat kaitannya dengan pendidikan, dimana di harapkan bahwa dengan pendidikan yang tinggi maka orang tersebut akan semakin luas pula pengetahuannya. Namun bukan berarti seorang yang berpendidikan rendah mutlak berpengetahuan rendah pula. Masyarakat yang memeliki pengetahuan tentang malaria dengan baik akan mempengaruhi perilaku dari masyarakat itu sendiri (wawan, 2010 dalam (Wawan, 2010 dalam Prihatin, 2012)

Pengaruh Tidak Langsung Sikap Terhadap Kejadian Malaria Melewati Lingkungan Fisik Di Desa Alim Mebung Dan Desa Nurbenlelang Kecamatan Alor Tengah Utara Kabupaten Alor Provinsi NTT Tahun 2018 Uji hipotesis dengan pendekatan SEM menghasilkan koefisien jalur pengaruh tidak langsung sikap terhadap kejadian malaria melewati lingkungan fisik dengan nilai $t$-vulues $-2,72$ sehinga hubungan antara ketiga jalur variabel tersebut signifikan. Sikap yang positif akan cenderung membawa masyarakat untuk mencegah terjadinya penularan penyakit termasuk penyakit malaria. Sikap yang dimaksud dalam penelitian ini adalah tentang kebiasaan diluar rumah. Hasil ini sesuai dengan basil 
penelitian (Erlan dkk, 2008) yang menyatakan bahwa buruknya kebiasan dan sikap masyarakat merupakan salah satu faktor pendukung penyebaran malaria.

\section{SIMPULAN}

1. Pengetahuan $(-0,51)$ dan sikap $(0,76)$ tidak memiliki pengaruh langsung terhadap lingkungan fisik.

2. Pengetahuan (2,89), sikap $(2,72)$ dan lingkungan fisik $(10,56)$ memiliki pengaruh langsung terhadap kejadian malaria.

3. pengetahuan $(2,89)$ dan sikap $(-2,72)$ memiliki pengaruh terhadap kejadian malaria melewati lingkungan fisik.

\section{SARAN}

1. Kerja sama antar lintas program (Itegrasi dengan program KIA dan imunisasi serta kesehatan lingkungan) dan lintas sektoral (kecamatan, humas, pendidikan, peternakan, pertanian, kehutanan, PKK, dan lain-lain) dalam mencegah malaria, sehinga kasus malaria tidak meningkat.

2. Perlu meningkatkan upaya promotif dengan cara melakukan penyuluhan tentang pengetahuan, sikap, lingkungan fisik, dan malaria agar masyarakat bias tahu cara penanggulangan lebih waspada terhadap kejadian malaria.

3. Melakukan upaya penyuluhan secara intensif guna memberikan pemahaman pada masyarakat tentang cara mencegah dan malaria dengan menata lingkungan serta membiasakan perilaku hidup bersih dan sehat.

\section{DAFTAR PUSTAKA}

Adebayo, A. M., Akinyemi, O. O. and Cadmus, E. O. (2015) 'Knowledge of malaria prevention among

pregnant women and female caregivers of under-five children in rural southwest Nigeria', PeerJ, 3, pp. 1-13.

Available at: http://www.depkes.go.id/ (Akses: 26 Augustus 2018) Southern Ethiopia: CommunityBased Cross-Sectional Study', Journal of Tropical Diseases, 05(03), pp. 1-11

Dinkes Kab Alor. 2018. Profil Dines Kesehatan Kabupaten Alor Tahun 2018.

Prov NTT. 2015. Profil Dines Kesehatan Provinsi Nusa Tenggara Timur Tahun 2015, 1 juni 2016.

Khairy, S. et al. 2017. 'Knowledge, attitude and practice about malaria in south-western Saudi Arabia: A household-based cross-sectional survey', Journal of Infection and Public Health. King Saud Bin Abdulaziz University for Health Sciences, 10(5), pp. 499-506.

Yaya, S. et al. (2017) 'Knowledge of prevention, cause, symptom and practices of malaria among women in Burkina Faso', PLoS ONE, 12(7), pp. 1-14.

Puskesmas Mebung. 2018. profil Puskesmas Mebung kabupaten Alor tahun 2018.

Notoatmodjo, S. 2011. Kesehatan Masyarakat Ilmu dan Seni. Jakarta : Rineka Cipta.

Wawan A. dan M. Dewi. (2011). Pengetahuan, Sikap dan Perilaku Manusia. Yogyakarta: Nuha Medika. Hal. 1-12

Prihatin, D. (2012) Kejadian Malaria Di Wilayah Kerja Puskesmas Mantangai Kabupaten Kapuas Provinsi Kalimantan Tengah Tahun 2012. Fakultas Kesehatan Kesehatan Masyarakat Program Sarjana Kesehatan

Masyarakat Peminatan Kebidanan Komunitas Depok Juli 2012

Erlan, et.al. (2008). Perilaku Kesehatan Masyarakat Kaitannya dengan Kejadian Malaria di Wilayah Kerja Puskesmas Kasimbar Kabupaten Paringi Moutong Sulawesi Tengah. Tesis. Universitas hasanuddin 